\title{
Hepatitis B prevalence, risk factors, infection awareness and disease knowledge among inmates: a cross-sectional study in Switzerland's largest pre-trial prison
}

Laurent Gétaz ${ }^{1,2}$, Alejandra Casillas ${ }^{1}$, Claire-Anne Siegrist ${ }^{3,4}$, François

Chappuis ${ }^{2}$, Giuseppe Togni ${ }^{5}$, Nguyen-Toan Tran ${ }^{1,6}$, Stéphanie Baggio', Francesco Negro ${ }^{7}$, Jean-Michel Gaspoz ${ }^{8}$, Hans Wolff ${ }^{1}$

${ }^{1}$ Division of Prison Health, Geneva University Hospitals and University of Geneva, Geneva, Switzerland

${ }^{2}$ Division of Tropical and Humanitarian Medicine, Geneva University Hospitals and University of Geneva, Geneva, Switzerland

${ }^{3}$ Department of Pathology and Immunology, University of Geneva, Geneva, Switzerland

${ }^{4}$ World Health Organization Collaborating Centre for Vaccine Immunology, University of Geneva, Geneva, Switzerland

${ }^{5}$ Unilabs, Coppet, Switzerland

${ }^{6}$ Australian Centre for Public and Population Health Research, Faculty of Health, University of Technology, Sydney, Australia

${ }^{7}$ Division of Gastroenterology and Hepatology and Division of Clinical Pathology, University Hospital, Geneva, Switzerland

${ }^{8}$ Department of Primary Care, Community Medicine, and Emergencies, Geneva University Hospitals and University of Geneva, Geneva, Switzerland

\section{Correspondence to:}

Dr Laurent Gétaz

Chemin du Petit Bel Air 2

1226 Thônex

Switzerland

laurent.getaz@hcuge.ch
Background Hepatitis B virus (HBV) is a major health concern in prison, but data are scarce in European prisons. This study aims to measure the prevalence of HBV infection, risk factors, awareness about infection, and HBV knowledge among inmates in Switzerland's largest pre-trial prison.

Methods Serological blood tests (HBsAg, anti-HBs, and anti-HBc) and a standardized socio-demographic and sexual health survey were offered to consenting prisoners in 2009 and 2011. HBV knowledge was assessed using a standardized questionnaire among participants recruited in 2009.

Findings A total of 273 male participants were included in the study (116 participants answered the HBV knowledge survey), with $38.1 \%$ originating from Eastern Europe, 28.2\% from sub-Saharan Africa, $14.3 \%$ from North Africa, and 9.5\% from Latin America. The prevalence of anti-HBc (resolved/chronic infection) was 38.2\% and the prevalence of HBsAg (chronic infection) was 5.9\%; 14\% of participants had vaccine-acquired immunity (anti-HBs positive/anti-HBc negative). We estimated that $15.5 \%$ of people living in Geneva having chronic infection go through the Geneva's prison. Region of origin was significantly associated with chronic/resolved HBV infection $(P<0.001)$ : $72.2 \%$ of participants from sub-Saharan African, 34.6\% from Eastern Europe and 13.2\% from other regions. In terms of chronic infection, $15.6 \%$ of participants from sub-Saharan Africa were positive for $\mathrm{HBsAg}$, vs $2 \%$ of those from other regions $(P<0.001)$. In stratified analyses, region of origin remained significantly associated with HBV infection. Among those with chronic infection, only $12.5 \%$ were aware of their status. A minority of inmates knew how HBV could be transmitted.

Conclusions The primary factor associated with HBV infection in this study was the geographical region of origin of participants. Given the high HBV prevalence found in this prison population, a targeted testing and vaccination approach based on prisoners' region of origin would be a cost-effective strategy when resources are limited. Additionally, identification of at-risk people should not rely on sensitive questions nor self-reported history of HBV. An inclusive approach to global health needs to incorporate prison population, as incarcerated people have a disproportionate burden of HBV infection and because an important proportion of hard-to-reach chronic HBV infected people go through the incarceration system. 
Hepatitis B virus (HBV) infection is a significant public health problem in prison settings with a global incidence estimate of 0.8\%-3.8\% per year [1-3]. Studies in the United States show that up to 3.7\% of prisoners suffer from chronic hepatitis B. The proportion is higher in European prisons (4.4\% in Denmark, 6.5\% in Belgium) [4]. The prevalence of anti-HBc antibodies (indicating infection at some point in time) in prisoners is 20\%-25\% in the United States with a wider range in Europe (9\% in Ireland, 58\% in Greece) $[4,5]$.

There is a higher risk of HBV transmission in prison settings due to the lack of knowledge about HBV transmission modes [6], frequent and unprotected sexual intercourse, injection drug use (IDU), tattooing and other forms of skin piercing, and trauma $[2,5,7]$. The time period following prison release is also important in terms of increased risky behaviours (IDU and unsafe sex) [8]. Crofts et al. [9] showed that the annual incidence rate of HBV (per 100 person years) between two separate incarcerations was $12.6 \%$ (10 of 99 individuals seroconverted at subsequent entry). Such findings highlight the potential benefit of addressing hepatitis B prevention during imprisonment [9].

Prison settings provide a unique opportunity to implement HBV infection control measures for incarcerated individuals, thus reducing transmission within and outside the prison population [5]. However, given the epidemiological variability of HBV in European prisons, HBV prevention, and transmission control should be tailored to the local carceral context. This study aims to determine the prevalence of HBV serological markers, their associated risk factors, infection awareness and knowledge about modes of transmission/protection among inmates of the Champ-Dollon prison in Geneva, the largest pre-trial detention center in Switzerland.

\section{METHODS}

\section{Study population and data extraction}

A cross-sectional study was conducted at the Champ-Dollon pre-trial prison, at two distinct time points (2009 and 2011). During two varicella outbreaks, we conveniently offered to consenting participants of entire affected prison units a blood test and structured socio-demographic survey. There were no exclusion criteria. All questions were administered by a physician. The structured questionnaire included socio-demographic data, drug use, and sexual behaviour history (Table S1 in Online Supplementary Document). Participants recruited in 2009 also agreed to answer a previously validated questionnaire about hepatitis B transmission and protection modes [6]. Consent forms and questionnaires were developed in nine languages (English, French, German, Italian, Spanish, Albanian, Russian, Chinese, and Greek). All data were anonymized. Parts of the survey were submitted three to five days after the blood test. During this period, seven participants were released and had therefore some missing data. Of note, there was no HBV-focused intervention between 2009 and 2011 that could have influenced the results. The Clinical Ethics Research Committee of the University Hospitals of Geneva (HUG) approved the study (EC: 09-137).

\section{Laboratory and data analysis}

Every participant underwent serological testing for HBV surface antigen (HBsAg), antibodies against HBV core antigen (anti-HBc) and antibodies against surface antigen (anti-HBs) (EIA Architect system, Unilabs laboratory, Geneva). HBsAg positivity signalled chronic infection. The presence of anti-HBc antibodies and negative HBsAg indicated resolved/prior infection. The presence of anti-HBs (>10UI/l) in the absence of HBsAg and anti-HBc indicated vaccine-acquired immunity, even if occult HBV infections could not be excluded. These cases are rare [10] and were not considered as a specific HBV status in our study.

Continuous variables were summarized as mean and standard deviation, and categorical variables as absolute and relative frequencies. We calculated 95\% confidence intervals of prevalence ratios [95\% confidence interval CI] using Wilson's score interval. We also estimated how many people living in the canton of Geneva and having chronic HBV are susceptible to go through the correctional system. For this purpose, we used data on the number of adults living in the canton of Geneva (381000 adults aged more than 18 years), the number of people being incarcerated each year in Geneva (1789 adults), the prevalence rate of HBV in the Swiss population (0.18\%), and the prevalence rate of HBV in the Champ-Dollon prison estimated in this study [11-13].

Differences between groups were then tested using the $\chi^{2}$ test. The Fisher exact test was used when the expected value in $2 \times 2$ contingency tables was less than 5 . Association between HBV infection (chronic or resolved) and other categorical variables (age, gender, region of origin) was evaluated in bivariate anal- 
ysis. Participants with missing data were not included in the related analyses. Region of origin encompassed six regions of the world for participants' home countries: Western Europe, Eastern Europe and the Balkans, North Africa, Sub-Saharan Africa, Latin America, and Asia. We stratified the study's serological results based on known country-level HBsAg prevalence (HBV endemicity), using the WHO classification and recent publications: "low" (<2.00\%), "lower-intermediate" (2.00-4.99\%), "higher-intermediate" (5.00-7.99\%), and "high" ( $\geq 8.00 \%)(10-13)$. A logistic regression was performed to identify factors associated with $\mathrm{HBV}$ infection. All variables with $\mathrm{p}$-value $<0.20$ in the bivariate analyses were included in a multivariate model. Since Champ-Dollon is a pre-trial prison with a high turnover of detainees, people incarcerated in 2009 were not the same as those incarcerated in 2011. All analyses were performed for the whole sample (2009 and 2011) and then separately for 2009 and 2011 to test whether there were significant differences between the two time points. The statistically significant level was set to $P<0.05$. All analyses were performed using SPSS for Windows (version 17.0) (IBM, Armonk, NY, USA) or OpenEpi (version 2.3.1) (open source software).

\section{RESULTS}

\section{Socio-demographic characteristics and sexual health risks}

Table 1 and Table 2 summarize the socio-demographic and sexual behaviour risks among the participants: out of 281 inmates, 273 agreed to participate in the study (116 in 2009, 157 in 2011, participation rate: $97.2 \%)$.

Table 1. Socio-demographic characteristics among inmates at the Champ Dollon prison in Geneva, Switzerland, $2009 \& 2011(\mathrm{n}=273)$

\begin{tabular}{|c|c|c|c|c|}
\hline Characteristics & Total & 2009 & 2011 & $P_{\text {-value }}^{*}$ \\
\hline \multicolumn{5}{|l|}{$\operatorname{Sex}(\%, n):$} \\
\hline Male & $100(273)$ & $100(116)$ & $100(157)$ & - \\
\hline \multicolumn{5}{|l|}{ Region of origin $(\%, \mathbf{n})$ : } \\
\hline Central and Eastern Europe & $38.1(104)$ & $36.2(42)$ & $39.5(62)$ & $<0.001$ \\
\hline Sub-saharan Africa & $28.2(77)$ & $31.9(37)$ & $25.5(40)$ & $<0.001$ \\
\hline North Africa & $14.3(39)$ & $21.6(25)$ & $8.9(14)$ & $<0.001$ \\
\hline Latin America & $9.5(26)$ & $2.5(3)$ & $14.7(23)$ & $<0.001$ \\
\hline Western Europe & $29.2(5)$ & $6.9(8)$ & $10.8(17)$ & $<0.001$ \\
\hline Asia & $0.7(2)$ & $0.9(1)$ & $0.6(1)$ & $<0.001$ \\
\hline Age (mean years, SD) & $29.8(9.0)$ & $27.7(7.2)$ & $30.9(8.8)$ & 0.002 \\
\hline \multicolumn{5}{|l|}{ Self-evaluated socioeconomic status (n, \%): } \\
\hline Low & $16.2(43)$ & $10.6(12)$ & $20.4(31)$ & 0.188 \\
\hline Moderate & $77.4(205)$ & $83.2(94)$ & $73.0(111)$ & 0.188 \\
\hline High & $6.4(17)$ & $6.2(7)$ & $6.6(10)$ & 0.188 \\
\hline \multicolumn{5}{|l|}{ Level of education (n, \%): } \\
\hline No school & $3.0(8)$ & $4.5(5)$ & $2.0(3)$ & 0.126 \\
\hline At least some primary school & $14.0(37)$ & $15.9(18)$ & $12.5(19)$ & 0.126 \\
\hline Finished primary school & $10.9(29)$ & $10.6(12)$ & $11.2(17)$ & 0.126 \\
\hline At least some secondary school & $21.6(57)$ & $15.9(18)$ & $25.7(39)$ & 0.126 \\
\hline Finished secondary school & $40.3(107)$ & $46.9(53)$ & $35.5(54)$ & 0.126 \\
\hline Some university education & $10.2(27)$ & $6.2(7)$ & $13.1(20)$ & 0.126 \\
\hline \multicolumn{5}{|l|}{ Type of living area in childhood $(n, \%): \dagger$} \\
\hline Rural & $19.8(23)$ & $19.8(23)$ & - & - \\
\hline Urban & $80.2(93)$ & $80.2(93)$ & - & - \\
\hline \multicolumn{5}{|l|}{ Legal status $(\mathrm{n}, \%): \dagger$} \\
\hline Undocumented & $63.7(76)$ & $63.7(76)$ & - & - \\
\hline Non-European migrant with residence permit in Switzerland & $22.1(25)$ & $22.1(25)$ & - & - \\
\hline Swiss or European passport & $10.6(12)$ & $10.6(12)$ & - & - \\
\hline
\end{tabular}

SD - standard deviation

* $\chi^{2}$ tests or Fisher exact tests for categorical outcomes and $t$ tests for continuous outcomes.

$\dagger$ Only asked to 113 out of 116 participants in 2009 
Table 2. Sexual health characteristics among inmates at the Champ-Dollon prison in Geneva, Switzerland, $2009 \& 2011(\mathrm{n}=273)$

\begin{tabular}{|c|c|c|c|c|}
\hline Characteristics $(\%, \mathrm{~N})$ & TotAL & 2009 & 2011 & P-value ${ }^{*}$ \\
\hline \multicolumn{5}{|l|}{ Sexual orientation: } \\
\hline Homosexual and/or bisexual & $2.3(6)$ & $2.7(3)$ & $2.0(3)$ & .807 \\
\hline Heterosexual & $97.7(258)$ & $97.3(109)$ & $98.0(149)$ & .807 \\
\hline \multicolumn{5}{|l|}{ Number of sexual partners over lifetime: } \\
\hline 0 & $0.4(1)$ & $0.9(1)$ & $0(0)$ & .132 \\
\hline 1 & $5.3(14)$ & $1.8(2)$ & $8.0(12)$ & .132 \\
\hline 2 to 5 & $21.3(56)$ & $21.2(24)$ & $21.3(32)$ & .132 \\
\hline 6 or more & $73.0(192)$ & $76.1(86)$ & $70.7(106)$ & .132 \\
\hline \multicolumn{5}{|c|}{ Number of sexual partners in the 6 months before incarceration: } \\
\hline 0 & $11.4(30)$ & $15.0(17)$ & $8.6(13)$ & .465 \\
\hline 1 & $42.7(113)$ & $39.8(45)$ & $45.0(68)$ & .465 \\
\hline 2 to 5 & $32.6(86)$ & $33.6(38)$ & $31.8(48)$ & .465 \\
\hline 6 or more & $13.3(35)$ & $11.6(13)$ & $14.6(22)$ & .465 \\
\hline \multicolumn{5}{|l|}{ Age of first sexual intercourse (years): } \\
\hline$\leq 16$ & $53.2(133)$ & $40.5(45)$ & $48.9(68)$ & .116 \\
\hline$>16$ & $46.8(117)$ & $59.5(66)$ & $51.1(71)$ & .116 \\
\hline \multicolumn{5}{|l|}{ Sexual intercourse with sex worker: } \\
\hline No & $47.2(125)$ & $52.2(59)$ & $43.4(66)$ & .349 \\
\hline Yes & $52.8(140)$ & $47.8(54)$ & $56.6(86)$ & .349 \\
\hline \multicolumn{5}{|l|}{ Use of condoms during sexual intercourse: } \\
\hline Always & $33.0(87)$ & $21.4(24)$ & $41.4(63)$ & $<.001$ \\
\hline Sometimes & $56.8(150)$ & $72.3(81)$ & $45.4(69)$ & $<.001$ \\
\hline Never & $10.2(27)$ & $6.3(7)$ & $13.2(20)$ & $<.001$ \\
\hline
\end{tabular}

Two thirds of the participants (63.7\%) were undocumented (no Swiss or European Union (EU) passport or residence permit in Switzerland) (Table 1), and 38.1\% originated from Central and Eastern Europe, 28.2\% from sub-Saharan Africa, 14.3\% from North Africa, 9.5\% from America Latin, 9.1\% from Western Europe, and 0.7\% from Asia. Mean age was 29.8 years (SD 9.0). Half of the participants (50.7\%) had completed high school. In terms of sexual health, $2.3 \%$ reported to be homosexual and/or bisexual. More than half $(53.0 \%)$ of the respondents reported having had sexual activities with sex workers and having experienced their first sexual encounter before the age of 16 . Two-thirds (67.0\%) reported occasional or no condom use. The only significant differences between 2009 and 2011 were age (older participants in 2011, $P=0.002$ ), region of origin (in 2011, there were fewer participants from North Africa and

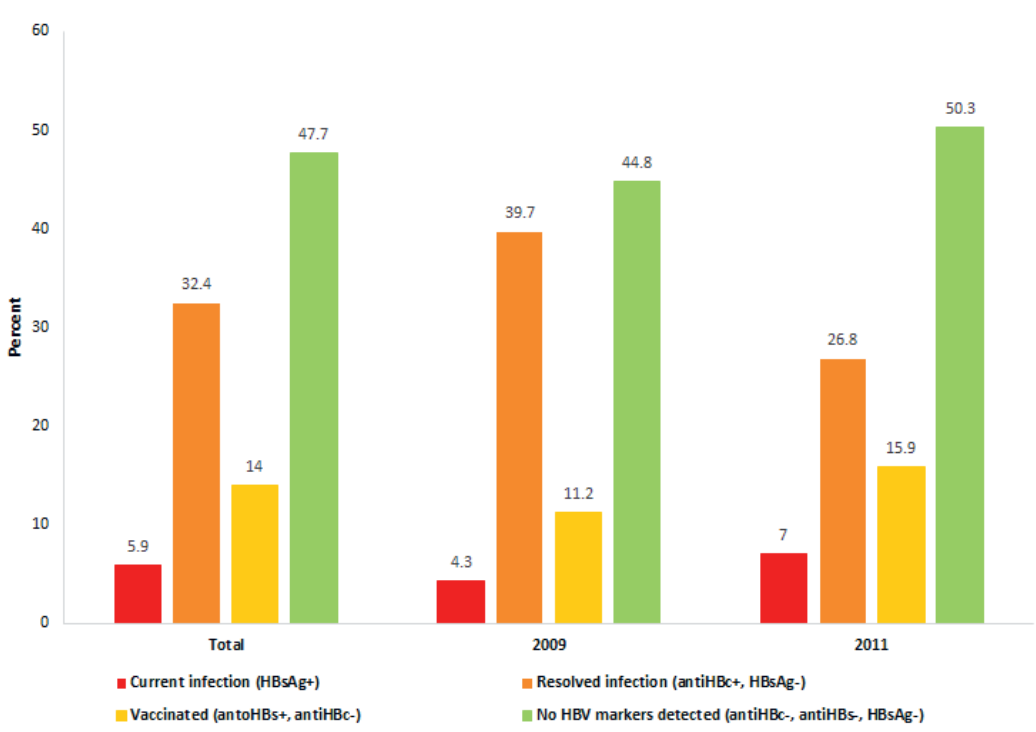

Figure 1. Hepatitis B markers among inmates at Champ-Dollon prison in Geneva, Switzerland, 2009 and $2011(\mathrm{n}=273)$. more from Latin America, $P<0.001)$, and use of condom (more participants reported "sometimes" in 2009, $P<0.001)$.

\section{Hepatitis B seroprevalence and region of origin}

Figure 1 summarizes the HBV serological profile of the study population: $5.9 \%$ (95\% CI $=3.6-9.3)$ had a chronic infection $(\mathrm{HBsAg}+), 32.4 \%(95 \% \mathrm{CI}=32.7-44.1)$ had resolved HBV (anti-HBc+, but HBsAg-), and $14.0 \%$ (95\% CI $=10.3-18.6)$ had a serological profile consistent with immunization (anti-HBc-, anti-HBs+). Just less than half of the inmates $(47.7 \%, 95 \%$ $\mathrm{CI}=41.9-53.7)$ had no detectable HBV markers, meaning that they were neither HBsAg carriers nor immune, and therefore susceptible to HBV infection. There was no significant difference between HBV status 
in 2009 and 2011 ( $P=0.131$ for the $\chi^{2}$ test). With a population of 381000 adults in Geneva and a prevalence rate of $0.18 \%$ of $\mathrm{HBV}$ in the Swiss population, we can estimate that 686 persons per year are infected in the general population $(381000 \times 0.0018)$. With 1789 adults incarcerated each year and a prevalence rate of $5.9 \%$ in Champ-Dollon prison, we can estimate that 106 persons are infected in the incarcerated population $(1789 \times 0.059)$. Therefore, $15.5 \%$ (106 out of 686 persons) of the infected persons go through Geneva's prison for a given year.

In terms of anti-HBc positivity (ever infected with HBV), 72.2\% (95\%IC: 61.9-81.4) from sub-Saharan Africa were positive, 34.6\% (95\%CI = 26.2-44.2) from Central and Eastern Europe, and 13.2\% (95\% CI= 7.7-21.6) from other regions (primarily Western Europe, Latin America, and North Africa) $(P<0.001)($ Table 3). The anti-HBc prevalence was statistically significant when aggregated by countries considered as "low" 9.1\% (6/66), "lower-intermediate" 22.7\% (17/75), "higher-intermediate" 46.3\% (25/54), and "high" $72.7 \%(56 / 77),(P<0.001)$. Among the eastern European block, 49.0\% of detainees from the "high-intermediate" countries of Romania and Albania were positive for anti-HBc, compared to only $21.8 \%$ of those from the other Eastern European and Balkan countries $(P=0.004)$. Sub-Saharan African region was associated with presence of HbsAg (chronic HBV infection) with a prevalence of $15.6 \%$ vs $2 \%$ participants from other regions, all combined $(P<0.001)$. HBsAg endemicity per country also followed a statistically significant difference $(P=0.001)$ : "low to lower-intermediate countries" $1.4 \%(2 / 141)$, vs "higher-intermediate to high countries" 10.7\% (14/131).

Table 3. Association between positive HBV surface antigen (HBsAg), positive core antibody (AntiHBc) and sociodemographic and sexual health characteristics among inmates at the Champ-Dollon prison in Geneva, Switzerland, $2009 \& 2011(\mathrm{n}=273)$

\begin{tabular}{|c|c|c|c|c|c|}
\hline & N & HBsAg + /TOTAL (\%) & P-value & AntilBBc + /TOtal $(\%)^{*}$ & P-value \\
\hline \multicolumn{6}{|l|}{ Region of origin: } \\
\hline Sub-Saharan Africa & 77 & $12(15.6 \%)$ & $<0.001 \dagger$ & $56(72.7 \%)$ & $<0.001$ \\
\hline Other regions & 196 & $4(2.0 \%)$ & & $48(24.6 \%) *$ & \\
\hline \multicolumn{6}{|l|}{ Age (years): } \\
\hline$\geq 28$ & 141 & $7(5.0 \%)$ & 0.51 & $54(38.6 \%)^{*}$ & 0.91 \\
\hline$<28$ & 132 & $9(6.8 \%)$ & & $50(37.9 \%)$ & \\
\hline \multicolumn{6}{|l|}{ Education level: } \\
\hline Secondary school & 191 & $8(4.2 \%)$ & $0.56 \dagger$ & $70(40.9 \%) *$ & 0.72 \\
\hline Never to secondary school & 74 & $5(6.8 \%)$ & & $29(39.2 \%)$ & \\
\hline \multicolumn{6}{|c|}{ Condom use for sexual protection: } \\
\hline Sometimes or never & 177 & $9(5.1 \%)$ & $0.73 \dagger$ & $70(39.5 \%) *$ & 0.41 \\
\hline Always use condoms & 87 & $6(6.9 \%)$ & & $30(34.5 \%)$ & 0.41 \\
\hline \multicolumn{6}{|c|}{ Man who has had sex with men: } \\
\hline Yes & 6 & $1(16.7 \%)$ & $0.60^{\dagger}$ & $4(66.7 \%)$ & $0.30 \dagger$ \\
\hline No & 258 & $14(5.4 \%)$ & & $96(37.2 \%) *$ & \\
\hline \multicolumn{6}{|c|}{ Number of sexual partners (lifetime): } \\
\hline 6 or more & 192 & $8(4.2 \%)$ & 0.29 & $70(36.5 \%)^{*}$ & 0.84 \\
\hline 0 to 5 & 71 & $6(8.5 \%)$ & & $27(38.0 \%)$ & \\
\hline \multicolumn{6}{|c|}{ Number of sexual partners (6 months before incarceration): } \\
\hline 6 or more & 35 & $2(5.7 \%)$ & $0.99 \dagger$ & $9(25.7 \%)$ & 0.12 \\
\hline 0 to 5 & 229 & $13(5.7 \%)$ & & $90(39.3 \%)^{*}$ & \\
\hline \multicolumn{6}{|c|}{ Age of first sexual intercourse (years): } \\
\hline$\leq 16$ & 133 & $6(4.5 \%)$ & 0.60 & $53(39.8 \%)$ & 0.25 \\
\hline$>16$ & 117 & $7(6.0 \%)$ & & $38(32.7 \%) *$ & \\
\hline \multicolumn{6}{|c|}{ Sexual intercourse with sex workers: } \\
\hline Never & 125 & $9(7.2 \%)$ & 0.31 & $44(35.2 \%)$ & 0.39 \\
\hline At least once & 140 & $6(4.3 \%)$ & & $56(40.3 \%) *$ & \\
\hline \multicolumn{6}{|l|}{ Injection drug use: } \\
\hline Yes & 16 & $0(0 \%)$ & $0.78 \dagger$ & $7(43.8 \%)$ & 0.65 \\
\hline No & 253 & $15(5.9 \%)$ & & $96(38.0 \%) *$ & \\
\hline \multicolumn{6}{|l|}{ Type of living area: } \\
\hline Rural & 23 & $0(0 \%)$ & $0.65 \dagger$ & $14(60.9 \%)$ & 0.07 \\
\hline Urban & 93 & $5(5.4 \%)$ & & $37(39.8 \%)$ & \\
\hline
\end{tabular}

* Not enough serum for antiHbc for one participant.

$\uparrow$ Fischer exact test.

†Only asked to 113 out of 116 participants in 2009 


\section{Hepatitis B seroprevalence and other factors}

In bivariate analysis (Table 3), the results showed no association between HBV infection (chronic or resolved) and age, education level, number of sexual partners, age of first sexual activity, history of sexual activity with sex workers, same-sex sexual activities, injection drug use, rural or urban living, or "non-use" of condoms. In further sensitivity tests including all factors with $P$-values $<0.20$ (multivariate regression checks) only region of origin was significantly associated with presence of anti-HBc. Disaggregated analyses for 2009 and 2011 yielded similar results (not shown in Table 3).

\section{Knowledge about infection and vaccination history}

Out of the 16 patients with chronic hepatitis B, 2 (12.5\%) knew about their status. The first 116 participants who joined the study also answered questions about vaccination history: $15.0 \%$ were certain about prior vaccination, of whom 35.3\% (5.3\% of all participants) reported reception of 3 doses. Eight had anti-HBs suggestive of vaccination, 7 had resolved HBV (anti-HBc without HBsAg) and 2 were susceptible to HBV. Among the 30 detainees who reported no vaccination, $46.7 \%$ were immune post hepatitis B infection (anti-HBc+), but 10.0\% had chronic hepatitis B (HBsAg+).

\section{Knowledge about transmission of and protection against $\mathrm{HBV}$}

Among the first 116 participants included in the study in 2009, 113 answered a questionnaire assessing their knowledge of and protection against HBV transmission (Table 4). Only 27\% of participants knew that HBV could be transmitted by syringe exchange, $21 \%$ by razors or toothbrushes exchange, and $19 \%$ through tattoos. Overall $21 \%$ and $27 \%$ stated that using condoms and sterile syringes, respectively, could prevent HBV infection.

Table 4. Knowledge about hepatitis B transmission and prevention modes among inmates at the Champ-Dollon prison in Geneva, Switzerland, 2009 ( $\mathrm{n}=113)$

\begin{tabular}{|c|c|}
\hline Questions & $\%(M)$ \\
\hline \multicolumn{2}{|l|}{ Can you get hepatitis B from having unprotected sex? } \\
\hline Yes & $24.8(28)$ \\
\hline No or I don't know & $75.2(85)$ \\
\hline \multicolumn{2}{|l|}{ Can you get hepatitis B from sharing needles? } \\
\hline Yes & $26.6(30)$ \\
\hline No or I don't know & $73.4(83)$ \\
\hline \multicolumn{2}{|c|}{ Can you get hepatitis B from sharing toothbrushes or razors? } \\
\hline Yes & $21.2(24)$ \\
\hline No or I don't know & $78.8(89)$ \\
\hline \multicolumn{2}{|l|}{ Can one get hepatitis B by eating contaminated food? } \\
\hline No & $9.7(10)$ \\
\hline Yes or I don't know & $90.3(103)$ \\
\hline \multicolumn{2}{|l|}{ Can you get hepatitis B from being tattooed? } \\
\hline Yes & $19.5(22)$ \\
\hline No or I don't know & $80.5(91)$ \\
\hline \multicolumn{2}{|c|}{ Can a baby be infected with hepatitis B at birth, when born to a hepatitis B positive mother? } \\
\hline Yes & $15.9(18)$ \\
\hline No or I don't know & $84.1(95)$ \\
\hline \multicolumn{2}{|c|}{ Can drinking alcohol make liver disease worse if you have hepatitis B? } \\
\hline Yes & $15.0(17)$ \\
\hline No or I don't know & $85.0(96)$ \\
\hline \multicolumn{2}{|c|}{ Can one avoid hepatitis B infection by using condoms during sexual intercourse? } \\
\hline Yes & $21.2(24)$ \\
\hline No or I don't know & $78.8(89)$ \\
\hline \multicolumn{2}{|c|}{ Can one avoid hepatitis B infection by using sterile needles? } \\
\hline Yes & $27.4(31)$ \\
\hline No or I don't know & $72.6(82)$ \\
\hline
\end{tabular}




\section{DISCUSSION}

\section{Hepatitis B seroprevalence}

With regard to chronic hepatitis B, 5.9\% of the surveyed population in Champ-Dollon were HBsAg carriers, which is 33 times higher than the proportion in the general Swiss population [14]. This prevalence ranks among the highest values recorded in prisons in Europe and in the United States [4,5,15]. Additionally, a simple estimation suggested that $15.5 \%$ of HBV infected people living in the Canton of Geneva go through the correctional system each year. Because these persons are among the most hard-to-reach in the community, the detention system has a civil responsibility facing the challenge of controlling these diseases. This is also a unique opportunity to treat this disease and protect other people of being infecting.

\section{HBV infection and associated risk factors.}

The differences in HBV seroprevalence by region of origin found in the study are similar to the differences found in the literature, even by pre-determined stratification classes. Countries in sub-Saharan Africa are characterized by high percentages of HBsAg positivity (greater than $8 \%$ ), which is reflected by the high prevalence found among migrants from these countries in Europe [16]. North African countries are classified at the "low" or "lower-intermediate" levels. In Western European countries, the prevalence is low. The epidemiology of hepatitis B in Eastern Europe (including Balkan countries) is more heterogeneous: Serbia, Croatia, Bosnia and Herzegovina, and Slovenia report low prevalence, while Albania and Romania have "high-intermediate" HBV endemicity [14,16-19]. About half (48\%) of the study population and $88 \%$ of chronic hepatitis B cases came from countries with "higher-intermediate" (Albania, Romania) or "high" (sub-Saharan Africa) endemicity levels of HBsAg. These concordant findings show that prevalence figures among the general population in the country of origin can be extrapolated to prison populations in order to estimate risk of HBV by region of origin.

Sexual health risk factors (number of sexual partners, reported age of first sexual intercourse, history of activity with sex workers, and "non-use" of condoms) were not significantly related to infection in our study. These factors are known to be associated with HBV transmission [20-22]. It is possible that the sensitive nature of these questions led to an under-reporting of these sexual behaviours by prisoners. This however underscores that in prison populations, asking these sensitive questions may not always be useful in selecting subpopulations that are most at risk for HBV, given that many patients will not answer the question accurately.

This study did not show a statistically significant correlation between low education and chronic hepatitis B, contrariwise to previous studies, which demonstrated a clear link between low education status and HBV infection $[20,23,24]$.

The relationship between age and hepatitis B is less clear in the literature: among some prisons in Europe, Australia and the United States, markers of HBV infection are higher in older age groups [25-27]. However, among prisons in sub-Saharan Africa (Nigeria, Ghana), younger age is associated with HBV infection $[28,29]$. We did not find evidence for this association in our sample. Further data are needed on this topic.

\section{HBV infection and knowledge about HBV status}

Knowledge of having been infected by HBV among seropositive inmates was very low. Among 16 inmates with chronic HBV infection, only 2 (12.5\%) knew that they were infected, which corresponds to values reported in the general Swiss population [30]. A previous study of medical files in this population (no systematic serological screening) showed a 1\% prevalence of self-reported chronic HBV [31]. This underestimate corroborates that the majority of people living with chronic HBV infection in this population are unaware of (or ignore) their status- thus re-affirming the necessity for active HBV surveillance in prison. Furthermore, among the inmates reporting prior vaccination, 29\% had antibody levels that would not ensure long-term protection (anti-HBs $<100$ ); $12 \%$ were HBV susceptible, and $41 \%$ possessed markers of past/resolved HBV infection. These results suggest that in the absence of serological markers, a verbal history about vaccination and immunity is not reliable in this population.

\section{Implications for HBV screening, vaccination strategies, and education}

HBV serological screening has two objectives: 1) to diagnose chronic HBV infection, and 2) to detect people who are not appropriately immunized and need vaccination. Studies that incorporate cost-effective- 
ness measures recommend routine screening for chronic HBV (HBsAg positive) when the pre-test probability in the population is higher than $2 \%$ and when access to treatment for the majority of diagnosed patients is ensured (58-100\% depending on the models) [32-34]. Access and adherence to the long antiviral treatment is challenging in the prison setting due to poor continuity of care and follow up, and risks of breakthrough resistance secondary to lapses in treatment [35]. Despite issues with treatment initiation, screening for HBV remains beneficial in the prison setting, as those diagnosed by routine screening could benefit from health education in order to 1) limit the risk of a downward evolution of the disease (for example, only $15 \%$ of our participants knew that alcohol consumption could worsen liver damage in the presence of HBV infection), and 2) modify unsafe behaviours that could increase the risk of further HBV transmission in prison and after release [36].

Given the prevalence of HBV in our study population, HBV prevention and control measures should be offered to inmates during their time in prison. This could benefit their health and also protect the community as a whole. For instance, Pisu, Meltzer, \& Lyerla [37] demonstrated that the health care system benefits from allocating resources for prison HBV vaccination programs, and the United States Center for Disease Control recommends routine HBV immunization, chronic HBV screening, and HBV preventive health education while in prison [3].

Because HBV infection and the region of origin are significantly associated in this population, it could be proposed that patients from "high-intermediate" and "high" level HBV countries (who actually make up about half of the prison population: Albania, Georgia, Bulgaria, and countries in Sub-Saharan Africa), receive systematic screening for resolved and chronic HBV (anti-HBc and HBsAg). Non-immune individuals should receive immunization, while chronic HBV patients would benefit from intensive educational and therapeutic programs. Those from countries with "low" or "lower-intermediate" HBV levels would be vaccinated without testing.

An American study in 2002 using a similar questionnaire showed that $75 \%$ of their prison participants were aware of the primary modes of HBV transmission (considered less than ideal) [6]. Our results indicate an even lower level of HBV knowledge, thus reinforcing the potential impact of educational programs. Weinbaum et al. [3] have demonstrated that educational programs that target HBV prevention in prison are effective.

Finally, stigmatization acts as a barrier for prevention and treatment. Indeed, it often prevents people from seeking screening and treatment. Stigmatization is largely due to ignorance about the disease. Therefore, the prison environment is a unique opportunity to propose adequate education, prevention, and treatment for people at risk of being infected [38]. Since migrants are likely to be discriminated against, efforts should be made to avoid further stigmatization due to this infectious disease.

\section{Limitations and strengths}

A limitation in this project is the convenience sample of the study. Nevertheless, this sample was representative of the prison population; recruitment bias was minor with a high participation rate (97\%), and no policy of attribution of cells according to the origin of the prisoners (or any other criterion) existed. The study population represented respectively one-fifth and one-third of all prisoners incarcerated at the time of recruitment in 2009 and 2011. Because participants were asked to answer questions about themselves in terms of education (self-assessment) and sexual health (taboo questions), this information may have been less reliable due to reporting bias and social desirability, given that the questionnaire was completed face-to-face with a physician. Among participants with a serological pattern compatible with a resolved HBV (anti-Hbc pos/HbsAg neg), occult HBV infections were not excluded. Since these cases are rare, under-evaluation of chronic HBV prevalence in the study population would be very limited [10]. Future studies could focus on occult HBV infection among inmates. It would give an idea of the number of these cases, even if it concerns a very small proportion of active HBV cases. In this population, data about vaccination was confusing and participants did not reliably report their vaccination history. In terms of study strengths, we highlight the participation rate of $97 \%$; these results are useful in the implementation of hepatitis B preventive measures in a population that lacks epidemiological data. It must be noted that this study population was entirely male and focused on a single prison in Switzerland. However, the study population is similar to that of other pre-trial Swiss prisons, which are also characterized by a high proportion of immigrants (81.4\%) and men (94\%) [39]. Therefore, these results are of importance to prison health providers in Switzerland, and also in all countries where the proportion of migrants in prison is high. In Europe, immigrants represent a high proportion of the correctional popu- 
lation. In 2012, foreigners accounted for $21 \%$ of the estimated 1.73 million people detained in the prisons of the 47 Member States of the Council of Europe. The vast majority of foreign detainees originated from low-income countries [40]. Therefore, an inclusive approach to global health needs to incorporate prison population, as incarcerated people have a disproportionate burden of HBV infection [41]. In addition to the risk of transmission in custody between inmates and to the staff, on release there is the risk of HBV being transmitted to the wider community, as infected inmates represent a risk for their partners at the return to freedom. Our results recall that origin must also be taken into account within the community among migrant populations native from HBV endemic countries.

\section{CONCLUSIONS}

The prevalence of chronic HBV infection was 5.9\% at the Champ-Dollon prison, 33 times higher than the general Swiss population [14]. The main risk factor for infection was region of origin. Other known socio-demographic risk factors for HBV were not reliable in our prison setting, thus limiting their use in risk-stratifying patients for hepatitis B. A targeted testing and vaccination approach based on the prisoner's region of origin is a potential control strategy, especially because an important proportion of the infected and hard-to-reach population go through the detention system. Patient information, education, and counselling on HBV transmission modes should be offered to all inmates. An inclusive approach to global health needs to incorporate prison population, as incarcerated people have a disproportionate burden of HBV infection.

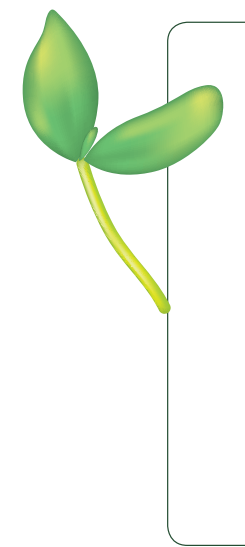

Acknowledgements: The authors would like to thank the medical and nurses' team as well as the director Mr Constantin Franziskakis of the prison Champ-Dollon for their active collaboration.

Funding: This work was supported by the Federal Office of Public Health (grant number 09.003678), Bern, Switzerland, and by the Medical Direction of the Geneva University Hospitals. The funders had no role in study design, data collection and analysis, decision to publish, or preparation of the manuscript.

Author contributions: Conceptualization: LG, CAS, FC, GT, FN, JMG, HW; Data curation: LG, GT, SB, HW; Formal analysis: LG, AC, NTT, SB, HW; Funding acquisition: LG, JMG, HW; Investigation: LG, GT, HW; Methodology: LG, CAS, FC, FN, JMG, HW; Project administration: LG; Visualization: LG, AC, NTT, HW; Writing - original draft: LG, AC; Writing - review \& editing: LG, AC, CAS, FC, GT, NTT, SB, FN, JMG, HW.

Competing interests: All authors have completed the ICMJE uniform disclosure form at http://www.icmje.org/ coi_disclosure.pdf (available upon request from the corresponding author) and declare no conflict of interest.

1 Gough E, Kempf MC, Graham L, Manzanero M, Hook EW, Bartolucci A, et al. HIV and Hepatitis B and C incidence rates in US correctional populations and high risk groups: a systematic review and meta-analysis. BMC Public Health. 2010;10:777. Medline:21176146 doi:10.1186/1471-2458-10-777

2 Khan AJ, Simard EP, Bower WA, Wurtzel HL, Khristova M, Wagner KD, et al. Ongoing transmission of hepatitis B virus infection among inmates at a state correctional facility. Am J Public Health. 2005;95:1793-9. Medline:16186457 doi:10.2105/AJPH.2004.047753

3 Weinbaum C, Lyerla R, Margolis HS, Centers for Disease control and Prevention. Prevention and control of infections with hepatitis viruses in correctional settings. Centers for Disease Control and Prevention. MMWR Recomm Rep. 2003;52:136. Medline: 12562146

4 Todts S, Fonck K, Colebunders R, Vercauteren G, Driesen K, Uydebrouck M, et al. Tuberculosis, HIV, hepatitis B and risk behaviour in a Belgian prison. Arch Public Health. 1997;55:87-97.

5 Hunt DR, Saab S. Viral hepatitis in incarcerated adults: a medical and public health concern. Am J Gastroenterol. 2009;104:1024-31. Medline:19240708 doi:10.1038/ajg.2008.143

6 Vallabhaneni S, Macalino GE, Reinert SE, Schwartzapfel B, Wolf FA, Rich JD. Prisoners' attitudes toward Hepatitis B vaccination. Prev Med. 2004;38:828-33. Medline:15193905 doi:10.1016/j.ypmed.2003.12.024

7 Jafari S, Buxton JA, Afshar K, Copes R, Baharlou S. Tattooing and risk of hepatitis B: a systematic review and meta-analysis. Can J Public Health. 2012;103:207-12. Medline:22905640

8 Glaser JB, Greifinger RB. Correctional health care: a public health opportunity. Ann Intern Med. 1993;118:139-45. Medline:8416310 doi:10.7326/0003-4819-118-2-199301150-00010

9 Crofts N, Stewart T, Hearne P, Ping XY, Breshkin AM, Locarnini SA. Spread of bloodborne viruses among Australian prison entrants. BMJ. 1995;310:285-8. Medline:7866168 doi:10.1136/bmj.310.6975.285 
10 Hollinger FB, Sood G. Occult hepatitis B virus infection: a covert operation. J Viral Hepat. 2010;17:1-15. Medline:20002296 doi:10.1111/j.1365-2893.2009.01245.x

11 OCSTAT. Mémento statistique du Canton de Genčve. Geneva: Switzerland: Canton de Genčve, 2015 2015. Report No.

12 OCSTAT. Entrées et journées de détention ř la Prison de Champ-Dollon, depuis 1985. Canton de Genčve; 2016.

13 Sakem B, Madaliński K, Nydegger U, Stępień M, Godzik P, Kołakowska A, et al. Hepatitis C virus epidemiology and prevention in Polish and Swiss population - similar and contrasting experiences. Ann Agric Environ Med. 2016;23:425-31. Medline:27660862 doi:10.5604/12321966.1219181

14 Schweitzer A, Horn J, Mikolajczyk RT, Krause G, Ott JJ. Estimations of worldwide prevalence of chronic hepatitis B virus infection: a systematic review of data published between 1965 and 2013. Lancet. 2015;386:1546-55. Medline:26231459 doi:10.1016/S0140-6736(15)61412-X

15 Hennessey KA, Kim AA, Griffin V, Collins NT, Weinbaum CM, Sabin K. Prevalence of infection with hepatitis B and C viruses and co-infection with HIV in three jails: a case for viral hepatitis prevention in jails in the United States. J Urban Health. 2009;86:93-105. Medline:18622707 doi:10.1007/s11524-008-9305-8

16 Majori S, Baldo V, Tommasi I, Malizia M, Floreani A, Monteiro G, et al. Hepatitis A, B, and C infection in a community of sub-Saharan immigrants living in Verona (Italy). J Travel Med. 2008;15:323-7. Medline:19006505 doi:10.1111/j.17088305.2008.00230.x

17 Durro V, Qyra S. Trends in prevalence of hepatitis B virus infection among Albanian blood donors, 1999-2009. Virol J. 2011;8:96. Medline:21375724 doi:10.1186/1743-422X-8-96

18 Hwang EW, Cheung R. Global epidemiology of hepatitis B virus (HBV) infection. N. J Med Sci. 2011;4:7-13.

19 Sbai A, Baha W, Ougabrai H, Allalia T, Dersi N, Lazaar F, et al. Hepatitis B prevalence and risk factors in Morocco. Pathol Biol (Paris). 2012;60:e65-9. Medline:21816547 doi:10.1016/j.patbio.2011.06.001

20 Corona R, Caprilli F, Giglio A, Stroffolini T, Tosti ME, Gentili G, et al. Risk factors for hepatitis B virus infection among heterosexuals attending a sexually transmitted diseases clinic in Italy: role of genital ulcerative diseases. J Med Virol. 1996;48:262-6. Medline:8801287 doi:10.1002/(SICI)1096-9071(199603)48:3<262::AID-JMV8>3.0.CO;2-6

21 Ferreira RC, Rodrigues FP, Teles SA, Lopes CLR, Motta-Castro ARC, Novais ACM, et al. Prevalence of hepatitis B virus and risk factors in Brazilian non-injecting drug users. J Med Virol. 2009;81:602-9. Medline:19235862 doi:10.1002/jmv.21464

22 Nascimento MC, Mayaud P, Sabino EC, Torres KL, Franceschi S. Prevalence of hepatitis B and C serological markers among first-time blood donors in Brazil: a multi-center serosurvey. J Med Virol. 2008;80:53-7. Medline:18041005 doi:10.1002/jmv.21046

23 Pereira LMMB, Martelli CMT, Merchán-Hamann E, Montarroyos UR, Braga MC, de Lima MLC, et al. Population-based multicentric survey of hepatitis B infection and risk factor differences among three regions in Brazil. Am J Trop Med Hyg. 2009;81:240-7. Medline:19635877

24 Vahid T, Kafaee J, Yektaparast B, Alavian SM. Hepatitis B prevalence and risk factors in blood donors in Ghazvin, Iran. Hepat Mon. 2005;5:117-22.

25 Babudieri S, Longo B, Sarmati L, Starnini G, Dori L, Suligoi B, et al. Correlates of HIV, HBV, and HCV infections in a prison inmate population: results from a multicentre study in Italy. J Med Virol. 2005;76:311-7. Medline:15902712 doi:10.1002/jmv.20375

26 Butler T, Boonwaat L, Hailstone S, Falconer T, Lems P, Ginley T, et al. The 2004 Australian prison entrants' blood-borne virus and risk behaviour survey. Aust N Z J Public Health. 2007;31:44-50. Medline:17333608 doi:10.1111/j.17536405.2007.00009.x

27 Samuel MC, Doherty PM, Bulterys M, Jenison SA. Association between heroin use, needle sharing and tattoos received in prison with hepatitis B and C positivity among street-recruited injecting drug users in New Mexico, USA. Epidemiol Infect. 2001;127:475-84. Medline:11811881 doi:10.1017/S0950268801006197

28 Adjei AA, Armah HB, Gbagbo F, Ampofo WK, Boamah I, Adu-Gyamfi C, et al. Correlates of HIV, HBV, HCV and syphilis infections among prison inmates and officers in Ghana: A national multicenter study. BMC Infect Dis. 2008;8:33. Medline:18328097 doi:10.1186/1471-2334-8-33

29 Adoga MP, Banwat EB, Forbi JC, Nimzing L, Pam CR, Gyar SD, et al. Human immunonodeficiency virus, hepatitis B virus and hepatitis $C$ virus: sero-prevalence, co-infection and risk factors among prison inmates in Nasarawa State, Nigeria. J Infect Dev Ctries. 2009;3:539-47. Medline:19762972 doi:10.3855/jidc.472

30 Russmann S, Dowlatshahi EA, Printzen G, Habicht S, Reichen J, Zimmermann H. Prevalence and associated factors of viral hepatitis and transferrin elevations in 5036 patients admitted to the emergency room of a Swiss university hospital: cross-sectional study. BMC Gastroenterol. 2007;7:5. Medline:17280611 doi:10.1186/1471-230X-7-5

31 Wolff H, Sebo P, Haller DM, Eytan A, Niveau G, Bertrand D, et al. Health problems among detainees in Switzerland: a study using the ICPC-2 classification. BMC Public Health. 2011;11:245. Medline:21504562 doi:10.1186/1471-2458-11-245

32 Fretz R, Negro F, Bruggmann P, Lavanchy D, De Gottardi A, Pache I, et al. Hepatitis B and C in Switzerland - healthcare provider initiated testing for chronic hepatitis B and C infection. Swiss Med Wkly. 2013;143:w13793. Medline:23740193

33 Hutton DW, Tan D, So SK, Brandeau ML. Cost-effectiveness of screening and vaccinating Asian and Pacific Islander adults for hepatitis B. Ann Intern Med. 2007;147:460-9. Medline:17909207 doi:10.7326/0003-4819-147-7-200710020-00004

34 Rossi C, Schwartzman K, Oxlade O, Klein MB, Greenaway C. Hepatitis B screening and vaccination strategies for newly arrived adult Canadian immigrants and refugees: a cost-effectiveness analysis. PLoS One. 2013;8:e78548. Medline:24205255 doi:10.1371/journal.pone.0078548

35 Chotiyaputta W, Peterson C, Ditah FA, Goodwin D, Lok ASF. Persistence and adherence to nucleos(t)ide analogue treatment for chronic hepatitis B. J Hepatol. 2011;54:12-8. Medline:20888661 doi:10.1016/j.jhep.2010.06.016 
36 Awofeso N. Hepatitis B vaccination in prisons. Bull World Health Organ. 2002;80:569-74. Medline:12163921

37 Pisu M, Meltzer MI, Lyerla R. Cost-effectiveness of hepatitis B vaccination of prison inmates. Vaccine. 2002;21:312-21. Medline:12450707 doi:10.1016/S0264-410X(02)00457-7

38 Kamarulzaman A, Reid SE, Schwitters A, Wiessing L, El-Bassel N, Dolan K, et al. Prevention of transmission of HIV, hepatitis B virus, hepatitis C virus, and tuberculosis in prisoners. Lancet. 2016;388:1115-26. Medline:27427456 doi:10.1016/ S0140-6736(16)30769-3

39 Office SFS. Prisons, pre-trial detention: data, indicators. SFSO, 2010. Report.

40 Aebi MF, Delgrande N. Coucil of Europe, Annual penal statistics. Strasbourg: Council of Europe, 2011 2011. Report No.: SPACE 1.

41 Rich JD, Beckwith CG, Macmadu A, Marshall BDL, Brinkley-Rubinstein L, Amon JJ, et al. Clinical care of incarcerated people with HIV, viral hepatitis, or tuberculosis. Lancet. 2016;388:1103-14. Medline:27427452 doi:10.1016/S01406736(16)30379-8 